УКД 37

DOI $10.21661 / r-530047$

\title{
А.В. Князева
}

\section{СОВРЕМЕННЫЕ ПРОБЛЕМЫ ИЗУЧЕНИЯ}

\section{ИЗОБРАЗИТЕЛЬНОГО ИСКУССТВА В УСЛОВИЯХ ИНКЛЮЗИИ}

Аннотация: в статье раскрыта проблематика изучения изобразительного искусства в условиях инклюзии, описан отечественный и зарубежный опыт образования в инклюзивной среде. Для решения поставленных проблем автор предлагает расширить содержание специальных обучающих программ, введение курсов по выбору и факультативов, а также создание вариативных моделей интегрированного обучения для педагогов и учителей, предполагающее использование арт-технологий, обеспечивающих эффективную реализацию интеграции ребенка с ОВЗ в пространство общего образования.

Ключевые слова: инклюзия, ограниченные возможности здоровья, образование, арт-технология, арт-терапия, изобразительное искусство.

\section{A.V. Knyazeva \\ MODERN PROBLEMS OF STUDYING ART IN AN INCLUSIVE ENVIRONMENT}

Abstract: the article focuses on the problems of studying art in the context of inclusion, describes the Russian and foreign experience of education in an inclusive environment. In order to address the issues, it is suggested to expand the content of the existing special education programs, introduce elective courses and extracurriculars, as well as create variatiable intergrative learning models for teachers, which suggest the use of art technologies that effectively include children with special needs into the general educational process.

Keywords: inclusion, special health needs, education, art, art technology, art therapy. 
Актуальность построения качественно новой образовательной системы в целом и инклюзивного в частности продиктована изменениями социально-экономических условий в России. Современная социальная ситуация далека от гармоничной. Не качественные социально-экономические условия снижают уровень жизни в субъектах Российской Федерации и по всей стране. Быстрый научно-технический прогресс, изменение методов производства, появление новых направлений производства и профессиональной деятельности обязывают человека постоянно развиваться, адаптироваться в обществе, узнавать, менять свой образ жизни. Отражение таких изменений мы видим в нашем обществе. Наше общество состоит из разных людей. И не каждый другой может быть одинаково принят обществом. Но само общество и его социальные институты (образование, культура, рынок труда и т. д.) вырабатывает нормы, которые регулируют социальное взаимодействие. Одной из таких норм, или социальных стереотипов, было отторжение людей с инвалидностью, их социальная изоляция.

Таким образом, идея включения в образование родилась в рамках масштабных изменений в понимании прав человека, их достоинства, самобытности и механизмов социальных и культурных процессов, которые определяют их статус и влияют на обеспечение их прав. Изменение отношения к людям с ограниченными возможностями стало лишь одним из проявлений этих изменений. И введение инклюзии возможно только на основе принципов демократизации и отсутствия какой-либо дискриминации.

Поэтому инклюзивное образование - это инновация в российской образовательной практике, инициированная родителями детей с ограниченными возможностями и учителями, психологами, которые верят в свою потребность не только в детях с ограниченными возможностями, но и во всем образовании в целом. Важно подчеркнуть, что инклюзивное образование в большинстве европейских стран и в России является одним из первых примеров борьбы родителей за права своих детей на образование, прецедентом для поведения родителей как реальных субъектов образовательного процесса. 
Не случайно введение понятия инклюзивного образования Саламанкской декларацией лиц с особыми потребностями (1994 г.) и принятие декларации ЮНЕСКО о культурном разнообразии (2001 г.) близки по времени своего появления: оба эти документа выражают не просто признание неоднородности общества и его культуры, но и изменение отношения в обществе к этому разнообразию - осознание его ценности, осознание ценности различий между людьми.

Анализ ситуации выявил ряд факторов, которые способствуют развитию инклюзии. В настоящее время в каждом классе учится определенное количество детей с нарушениями развития. Поэтому, помощь этим детям адаптироваться в обществе и в обучении является довольно актуальной задачей сегодня.

Именно поэтому следует подчеркнуть и пропагандировать имена и идеи выдающихся деятелей нашей страны и зарубежья, способствовавших интеграции «необычных» детей в общество и изучавших их особенности и возможности. В данной статье трудно назвать их всех, но некоторых из них - необходимо.

Так, крупнейший педагог-гуманист XVIII века И.Г. Песталоцци практиковал интеграционный подход к обучению и воспитанию (он работал с сиротами и инвалидами). Существенное влияние на развитие наук о детях (педологии, педагогики, педагогической антропологии и др.) оказал врач-невролог Зигмунд Фрейд, возведший к детству все трудности, проблемы и комплексы человека. Один из первых сурдопедагогов, Я Р. Перейра, своим физиологическим открытием доказал, что все виды сенсорного восприятия (он занимался проблемами глухонемых) в своей основе одинаковы и могут заменять друг друга.

Фрэнсис Гальтон разработал учение об индивидуальных психологических различиях, заложив основу диагностики психических качеств.

Особое место в ряду упомянутых нами ученых занимает первая женщина в Италии - доктор медицины, педолог, педагог, философ М. Монтессори, разработавшая педагогическую систему, гармонично вписавшуюся в развитие интеграционного образования и являющуюся для него базовой. 
Таким образом, у истоков инклюзии за рубежом, стояли такие выдающиеся ученые, как Я.Р. Перейра, И.Г. Песталоцци, Ф. Гальтон, 3. Фрейд, М. Монтессори и многие другие.

Российская педагогика решила проблему интеграции детей с ограниченными возможностями спустя два десятилетия, в 1990-х годах. Одним из первых, кто обосновал идею интегрированного обучения в России, был Л.С. Выготский. Он подчеркнул необходимость создания системы образования, в которой ребенок-инвалид не исключается из общества детей с нормальным развитием. А также те цифры, которые способствовали включению: Г.Я. Трошин В.П. Кащенко В.М. Бехтерев.

У истоков инклюзии в России (Г.Я. Трошин, В.П. Кащенко, В.М. Бехтерев, Л.С. Выготский и многие другие) яркие представители антропологической гуманистической концепции.

Рассмотрев деятелей основ инклюзивного образования, будет актуальным на сегодня рассмотреть некоторые проблемы.

Проблемы, отражающие нормативные и законодательные факторы, включают в себя отсутствие механизмов реализации законодательства; отсутствие законодательной базы, содержащей специальные положения об инклюзивном образовании.

Важными для решения проблем включения являются проблемы, раскрывающие педагогические факторы: перенасыщенность учебной программы; система оценки не приведена в соответствие с индивидуальными требованиями к образованию; непоследовательная система начального и непрерывного профессионального образования в области образования, направленная на максимальное раскрытие потенциала каждого ребенка; отсутствие преподавательского состава и методических основ, необходимых для обеспечения инклюзивного образования. Чтобы найти решение этих проблем, вам необходимо обратиться к нормативному документу, регулирующему работу с детьми-инвалидами и детьми-инвалидами в условиях инклюзии. 
Первым национальным нормативным документом, который содержит официальное толкование термина инклюзия, является закон «Об образовании инвалидов в Москве» от 28 апреля 2010 года №16. Он определяет инклюзивное образование как «совместное обучение (воспитание) включая организацию совместных образовательных занятий, досуга, различных видов дополнительного образования, людей с ограниченными возможностями и лиц без таких ограничений».

На основании данного документа современные исследования рассматривают различные формы инклюзии, особенно внутренней, когда ребенок, который имеет другую или более выраженную форму существующей нозологии, относится к классу детей с определенной нозологией. Также в документе указывается на создание определённых условий и использование эффективных технологии $[5$, с. 79$]$.

Поэтому инклюзивное образование должно стать следующим шагом в развитии образования не только для детей с ограниченными возможностями, но и для всей системы образования, что позволит достичь высоких результатов в образовании. Становится очевидным, что актуальность инклюзивного образования заключается в том, чтобы каждый ребенок, независимо от его физических и умственных способностей, мог удовлетворить потребность в образовании и равных правах.

Важным средством в решении проблем инклюзивного образования будет являться создание условий. Наиболее обобщенно требования к условиям получения образования детьми с ОВ3 отражены в проекте специального федерального государственного стандарта начального школьного образования детей с OB3 (Н.Н. Малофеев, О.С. Никольская, О.И. Кукушкина, 2010). В нем говорится о том, что нужно создать среду, адекватную общим и особым образовательным потребностям, физически и эмоционально комфортной для ребенка с OB3, открытой для его родителей (законных представителей).

Таким образом, можно говорить о целостной системе специальных образовательных условий, начиная от предельно общих до частно-специфических и индивидуально-ориентированных. 
Рассмотрим возможности специальных образовательных условий для реализации инклюзивного образования.

Первым условием является раннее выявление отклонений, которое требует создания и законодательного проектирования системы раннего вмешательства, которая является частью междисциплинарного командного подхода к работе специалистов.

Второе условие связано с профессиональной переподготовкой специалистов, обладающими готовностью и желанием работать с особыми детьми в массовых образовательных учреждениях.

Третьим условием является создание вариативных моделей интегрированного обучения, предполагающее разработку программ, технологий, организационных форм и условий, обеспечивающих эффективную реализацию интеграции ребенка с ОВ3 в пространство общего образования.

Четвертым условием является развитие личности обучающихся средствами искусства, получение эмоционально-ценностного опыта, выраженного в произведениях искусства, и опыта художественно творческой деятельности.

Следовательно, хотя инклюзивное образование в рамках общего образования в последнее время стало широко обсуждаемой и разработанной проблемой, инклюзивное художественное образование все еще остается педагогической инновацией. Конечно, дети-инвалиды ранее учились в учебных заведениях в области культуры и искусства, но такие случаи были эпизодическими. Сегодня дети из категории инвалидов нуждаются в качественном художественном образовании, особенно на ранней стадии.

В соответствии с решением задач нашего исследования рассмотрим четвертое условие развитие личности обучающихся средствами искусства. Социальное назначение искусства заключается в том, что оно через отражение своего предмета целостно и универсально взаимодействует и воздействует на ребенка. Одним из самых главных и необходимых моментов в развитии и воспитании любого ребенка является занятие изобразительной деятельностью. Она отражает 
уровень интеллектуального и эмоционального развития детей. В изобразительном искусстве воплощены все стороны нашего общества. Так, обычно различаются три функции искусства - познавательная, воспитательная, эстетическая - в их неразрывной органической связи. А также выделяют духовную, нравственную, лечебную и коррекционную.

Для обучения детей с ограниченными возможностями эффективно используются арт-технологии, которые оказывают влияние на развитие образного, абстрактного мышления, памяти, восприятия, воображения, гибкость мышления и др., а также арт-терапию.

Арт-технологии - это система последовательных действий педагога, направленных на решение учебно-воспитательных задач, с использованием различных видов искусства.

Арт-терапия - это лечение пластическим изобразительным творчеством, целью которого является выражение психоэмоционального состояния человека.

Обращение к такой терапии помогает ребенку лучше познать себя, свое состояние и глубины своей души. Быстрее развиваются и социализируются те дети, которые обучаются и воспитываются с применением арт-технологий.

В комплексе с другими учебными предметами они оказывают заметное коррекционно-развивающее действие на учащихся с особенностями в интеллектуальном развитии: влияют на его интеллектуальную, эмоциональную и двигательную сферу (главным образом моторику рук), развитие личностных качеств. Способствуют формированию эстетического восприятия, помогают в решении проблем социализации и адаптации «особого» ребенка.

С их помощью ребенок становится психически устойчивым к внешним факторам, рассудительным и активным. Рассматривая подробнее арт-технологию, выделим, что арт-технология - это обучение интеллектуальной деятельности средствами художественного творчества. По сути, это педагогика воспитания по самым обыкновенным общеобразовательным программам. 
Нельзя не оценить позитивное влияние арт-технологий на познавательный процесс ребенка и его развитие. Дети при таком подходе к обучению приобретают способность мыслить шире, давать более развернутые и полные ответы на вопросы преподавателей, учатся понимать искусство, тем самым развивая свои творческие способности. Помимо внутреннего развития ребенок лучше осваивается в социуме, проявляет ярко выраженный интерес к общению со своими сверстниками. Таким образом, еще можно помочь ребенку справляться и с негативными факторами, с которыми ему приходится сталкиваться не по своей воле.

Следовательно, для применения методов арт-терапии на практике педагогу необходимо овладеть арт-технологиями.

При множестве направлений в арт-технологиях одним из широко использованных является изотерапия и цветотерапия - лечебное воздействие средствами изобразительного искусства: рисованием, лепкой, декоративно-прикладным искусством.

Ребенок, который умеет рисовать, облегчает себе изучение других общеобразовательных предметов, ведь от рисования он получает огромную пользу, особенно развитие своего собственного логического мышления. В работу включаются двигательные и зрительные, мускульные и осязаемые анализаторы. Помимо этого, рисование помогает ребенку развивать память и внимание, учит его правильно воспринимать и анализировать ситуацию, сочинять и воображать. Изобразительная деятельность способствует развитию пространственных представлений, мелкой моторики и зрительно-моторной координации. Расширение запаса собственных знаний очень хорошо влияет на умственное развитие у детей.

К тому же, рисование - это процесс, который включает в себя экспериментирование, креативность и индивидуальный взгляд на объекты. На рисунке ребенок учится распознавать свои ошибки и как возможность создать что-то новое и уникальное. Изучая картины, выбирая палитру, совершенствуя работу, ребенок учится различать нюансы, видеть, сравнивать и обобщать общие и специальные возможности. 
Самое главное, что привлекает детей с точки зрения эстетического воспитания - это введение в глобальную культуру через изобразительное искусство.

Таким образом, с любого возраста ребенок может начать познавать себя и свой внутренний чувственный мир, открывать множество эмоций и чувств.

Более сложнее обстоит ситуация у детей с ОВ3, которая имеет ряд проблем.

Стоит отметить, одной из проблем внедрения в инклюзивное образование изобразительного искусства является ограниченность методических разработок и рекомендаций по использованию методов и приемов арт-технологий с детьми c OB3.

Поэтому, задачей разработки системы художественного образования и эстетического воспитания в условиях инклюзии является разработка и внедрение методов развивающего обучения, соответствующих психофизическим характеристикам особенных детей, с учетом особенностей когнитивных нарушений, нарушений познавательной деятельности и эмоционально-волевой сферы.

Конечно, на практике не всё так просто и современная образовательная система требует системного подхода. Тем не менее, учителя на данный момент имеют в распоряжении арсенал инновационных технологий, которые используют, чередуя и подбирая наиболее эффективные для каждого отдельного класса, с учетом всех особенностей учащихся, в том числе и детей с ОВ3.

Не менее интенсивную работу над устранением стереотипов в работе с особенными детьми нужно провести и среди педагогов, так как не многие уже имеющие стаж специалисты морально готовы к внедрению инклюзивных классов в учебное учреждение.

Не секрет, что в случае с инклюзивным художественным образованием особая нагрузка ложится на преподавателей, которые начинают свой путь в искусство, преобладающее большинство способных детей с особыми образовательными потребностями. Для педагогов это новая область деятельности, требующая знания особенностей детей с различными нарушениями в развитии, владения специфическими педагогическими технологиями и основами этики общения с учащимися данной категории. 
Итак, анализируя сегодняшнее состояние школ России, мы хорошо понимаем, что школы не готовы отвечать всем требованиям инклюзии. Это не значит, что нужно отвернуться от этой проблемы или принять факт неготовности как «приговор» инклюзии. Любая проблема должна быть переведена в область задачи. Только рассматривая совместно проблему готовности школы к обучению детей с ОВ3 и трудности, возникающие у самых обычных учеников, можно достичь полноценной инклюзии в этой школе [3].

Описанные выше проблемы являются существенным препятствием для эффективного внедрения художественного образования в инклюзивное образовательное пространство и для решения вышеперечисленных проблем на данном этапе, возможно расширение содержания общеобразовательных программ на всех этапах образования, введение курсов по выбору и факультативов, а также создание вариативных моделей интегрированного обучения, предполагающее использование арт-технологий, организационных форм и условий для занятий по изобразительному искусству, обеспечивающих эффективную реализацию интеграции ребенка с ОВ3 в пространство общего образования.

\section{Список литературы}

1. Гайдукевич С.Е. Средовой подход в инклюзивном образовании // Инклюзивное образование: состояние, проблемы, перспективы. - Минск: Четыре четверти, 2007. - С. 34.

2. Дмитриева Т.П. Разработка и реализация индивидуальной образовательной программы для детей с ограниченными возможностями здоровья в начальной школе / под ред. Е.В. Самсоновой; Т.П. Дмитриева. С.И. Сабельникова, Т.Ю. Хотылева. - М., 2012.

3. Ларина Н.В. Инклюзивное образование: проблемы и пути их решения [Электронный ресурс]. - Режим доступа: https://infourok.ru/inklyuzivnoeobrazovanie-problemi-i-puti-ih-resheniya-2455454.html

4. Письмо Минобрнауки России от 11 марта 2016 г. № ВК-452/07 «О введении ФГОС ОВЗ». 
5. Ратнер Ф.Л. Вопросы интеграции в трудах отечественных ученых // Маterials of the $\mathrm{X}$ International scientific and practical conference «Fundamental and applied science» (October 30 -November 7, 2014). - Англия, Шеффилд, 2014. - Volume 10. - Pedagogical sciences. Sheffield. Science and education LTD. - 88 c.; C. $79-83$.

6. Ратнер Ф.Л. Пути решения проблем инклюзивного образования за рубежом (на примере Мюнхенского Центра реабилитации развития) // «Идеи инклюзивной педагогики в свете современных требований к дошкольному, школьному и профессиональному образованию»: матер. Всеросс. научн.-практ. конф. с международным участием (Зеленодольск (Татарстан), 20 февраля 2013 г.). - Казань: Изд-во «Познание» Института экономики, управления и права, 2013. - 564 с.; C. $28-33$.

7. Ратнер Ф.Л. Интегрированное обучение детей с ограниченными возможностями в обществе здоровых детей / Ф.Л. Ратнер, А.Ю. Юсупова. - М.: ВЛАДОС, 2006. - 175 с.

8. Кулагина Л.В. Инклюзивное образование: проблемы и перспективы [Электронный pecypc]. - Режим доступа: https://multiurok.ru/files/essieinkliuzivnoie-obrazovaniie-probliemy-i-piers.html

\section{References}

1. Gaidukevich, S. E. (2007). Sredovoi podkhod v inkliuzivnom obrazovanii. Inkliuzivnoe obrazovanie, 34. Minsk: Chetyre chetverti.

2. Dmitrieva, T. P., Sabel'nikova, S. I., Khotyleva, T. Iu., \& Dmitrieva, T. P. (2012). Razrabotka i realizatsiia individual'noi obrazovatel'noi programmy dlia detei s ogranichennymi vozmozhnostiami zdorov'ia v nachal'noi shkole. Samsonovoi;; M.

3. Larina, N. V. Inkliuzivnoe obrazovanie: problemy i puti ikh resheniia. Retrieved from https://infourok.ru/inklyuzivnoe-obrazovanie-problemi-i-puti-ih-resheniya-2455454.html

4. Pis'mo Minobrnauki Rossii ot 11 marta 2016 g. VK-452. 
5. Ratner, F. L. (2014). Voprosy integratsii v trudakh otechestvennykh uchenykh. Materials of the X International scientific and practical conference "Fundamental and applied science" (October 30 -November 7, 2014), Angliia,, 88. Sheffild.

6. Ratner, F. L. (2013). Puti resheniia problem inkliuzivnogo obrazovaniia za rubezhom (na primere Miunkhenskogo Tsentra reabilitatsii razvitiia). "Idei inkliuzivnoi pedagogiki v svete sovremennykh trebovanii k doshkol'nomu, shkol'nomu i professional'nomu obrazovaniiu", Kazan': Izd, 564.

7. Ratner, F. L., \& Iusupova, A. Iu. (2006). Integrirovannoe obuchenie detei s ogranichennymi vozmozhnostiami v obshchestve zdorovykh detei., 175. M.: VLADOS.

8. Kulagina, L. V. Inkliuzivnoe obrazovanie: problemy i perspektivy. Retrieved from https://multiurok.ru/files/essie-inkliuzivnoie-obrazovaniie-probliemy-ipiers.html

Князева Александра Владимировна - учитель, МАОУ «СОШ № 22», Тюмень, Россия.

Knyazeva Aleksandra Vladimirovna - teacher, MAEI "Secondary School №22", Tyumen, Russia. 